\title{
Chambers but no echo
}

Environ. Commun. http://doi.org/ckqf (2018)

Nuclear energy is a controversial topic that ignites public debate. However, studies of discourse around nuclear energy typically focus on disasters in legacy news media. In contrast, Dorothee Arlt and colleagues from the University of Bern and University of Zurich examined how public debate leading up to the Swiss referendum on a nuclear energy policy (the Nuclear Withdrawal Initiative) unfolded over twitter.

Tweets were identified by keyword and hashtag searches in German, French and Italian during the four weeks leading up to the referendum. In total, 12,141 issue-related tweets were identified from 2,761 unique users. Network analysis revealed seven distinct communities that vary in group composition, size and ideological position. Tweet intensity peaked the day after the release of a public opinion poll indicating a tight race, one week before the day of and on the day of the referendum. Analysis of who replied to whom and with what frequency throughout the four weeks revealed that between $70-90 \%$ of replies went to users from other communities. These results stand in contrast to most studies on social media debates, particularly those in the US, which typically find evidence of echo chambers - two large ideologically separate groups that rarely interact. This may reflect the fact that the multi-party political system in Switzerland is less polarized and more consensus-oriented, even around controversial issues like nuclear energy.

Jenn Richler

Published online: 6 March 2018

https://doi.org/10.1038/s41560-018-0120-5 